Session \# 1365

\title{
Technological Aids in Advanced Calculus at New Mexico State University
}

\author{
Ross Staffeldt \\ New Mexico State University
}

\begin{abstract}
Technology in the form of the computer program Maple is proving to be an important aid to students learning advanced calculus. Availability of the program seems to help students while they learn to find and classify critical points and while they learn to set up and evaluate multiple integrals, to name two topics students find especially troublesome. For example, we have a number of goals for the course segment on the classification of critical points. In particular students should learn how to locate critical points graphically, by studying fields of gradient vectors and plots of level curves; formally, by solving explicitly for the zeroes of the gradient; and numerically, when formal solutions are infeasible. They should also learn to interpret the classification theorem verbally and graphically. The computations needed to locate the zeroes of the gradient of a function are almost always difficult, so it helps enormously to have the computer help solve equations. But a complete analysis of an example is a multi-step procedure, and, if it is all done on a computer, the procedure requires the use of many commands and thoughtful evaluation of computer output after each step.

So how does one go about making a computer program as large and sophisticated as Maple "available" to a typical group of students? We describe how the program is presented in digestible chunks, how other technology developed at NMSU helps provide adequate feedback to students, and how attaining a basic skill level contributes to the course grade. Materials created by the author are now being disseminated among other instructors of advanced calculus at NMSU. A preliminary assessment of the impact of the material on student learning is made below, and a wider study is planned.
\end{abstract}

\section{Goals}

Before any one of us would incorporate something new into teaching, each of us would consider reasons for the innovation, how familiar the innovation is to us, how we expect the innovation to affect the students, both in the short term and in the long run, and how we are going to manage

Proceedings of the 2001 American Society for Engineering Education Annual Conference \& Exposition Copyright (C) 2001, American Society for Engineering Education 
and support students under the new working conditions. The next sections of this report address these issues. In the final section of the paper we report on results of a survey of students who recently participated in a course in third semester calculus in which Maple was extensively used.

\section{Reasons for the innovation}

Let us illustrate one reason by examining a "before" sample of student work, shown in Figure 1. The assigned task is to locate and classify the critical points of the function $f(x, y)$. In class we have already reviewed the definition of critical points, the second derivative test, and illustrated the use of factoring to reduce the problem of locating critical points of a function of two variables to several instances of the problem of locating the point of intersection of two lines. The problems found in the following sample of my students' work motivated me to incorporate Maple into my courses on advanced calculus.

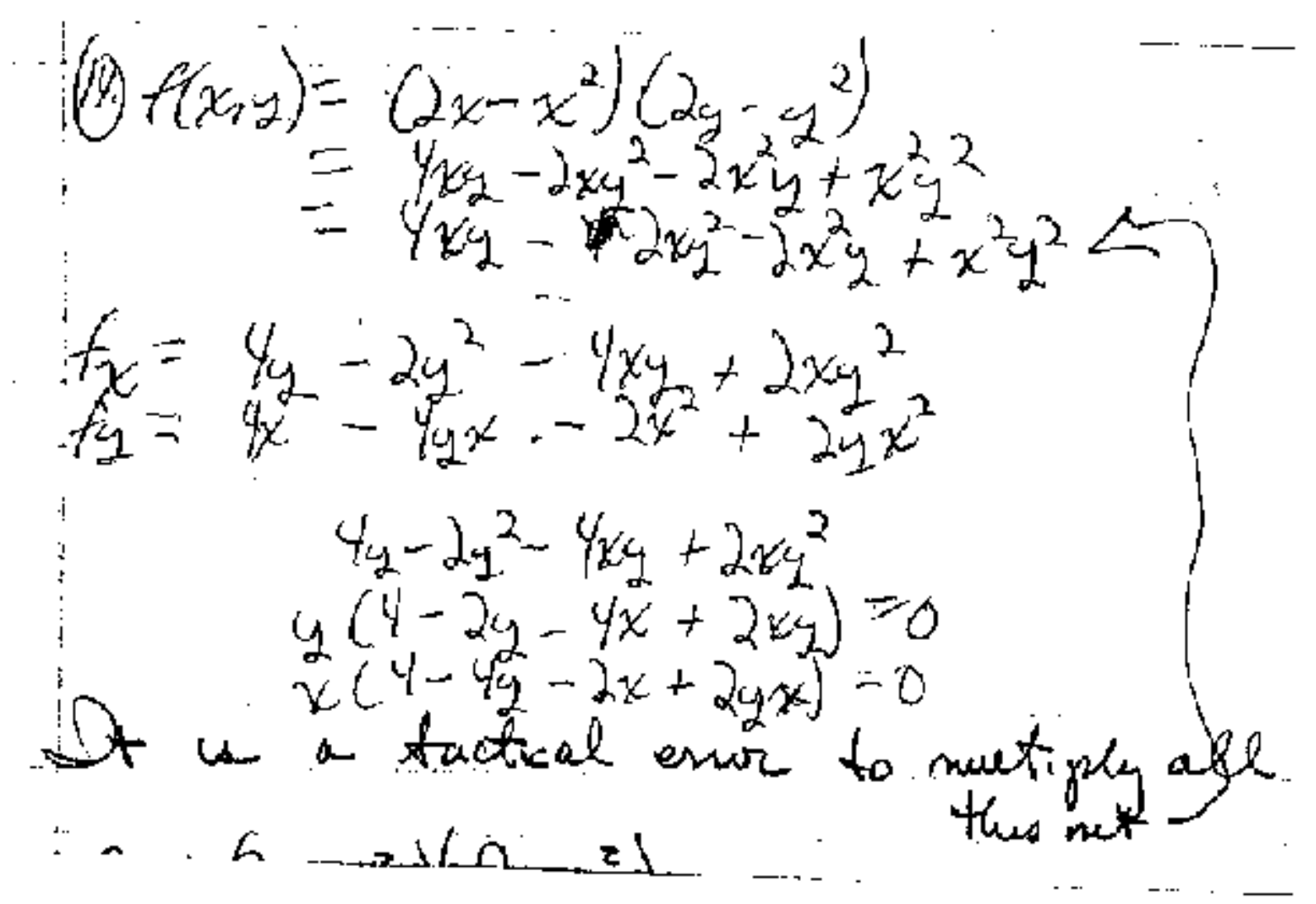

Figure 1. "Before" sample of students' work

We observe the student expand the function, which had been presented in partially factored form, into a sum of monomials; correctly differentiate the resulting sum of monomials term-by-term and get stuck trying to factor the results. The comment about the "tactical error" is mine. The student has not even gotten close to the part of the task that is the primary concern of the instructional unit. Since the author of our text ${ }^{5}$ devotes more pages to the study of critical points Proceedings of the 2001 American Society for Engineering Education Annual Conference \& Exposition Copyright (C) 2001, American Society for Engineering Education 
and their classification than to any other topic covered in our syllabus, this example of students' work is particularly disappointing. Students having similar difficulties used to be the rule rather than the exception, making evaluating students' progress through the material extremely frustrating. In 1997 I made my first experiments using Maple as a tool to assist students in the "heavy lifting " of equation solving, so that they could actually come to grips with value of the information obtained by solving the equations.

Before we continue, let us also pause to note that there are other questions raised by the sample attempt at the assigned task. For example, if the student understood that factoring would eventually be necessary, why wouldn't the student observe that the derivatives calculated from the original expression would already be partially factored? And, why doesn't the student try grouping terms according to common factors to generate a factorization of the expressions the student has obtained? In any case, problems doing algebra seem to be preventing the student from making progress here. Additional instances of situations in which students don't fully exploit geometric intuition and visualization skills arise in the discussion of multiple integrals. Thus, my main reason for encouraging the use of Maple is to provide a means by which students can develop geometric intuition as a means for coming to grips with the core material of advanced calculus. It is possible that students who develop confidence in their geometric intuition and visualization skills will develop greater appreciation for the use of algebra to describe geometric intuition. In the next sections I will discuss how I arrange for the students to develop Maple skills appropriate for advanced calculus. Since I believe that many of these points are applicable to other courses, the discussion in the next sections will be quite general.

\section{Preparing for a course using Maple}

Before attempting to introduce Maple as a tool for students, one must have some ideas about really essential segments of the course, how the computer will be helpful in demonstrating key concepts to the students, and what tools for working with the ideas the students should take away with them. On the other hand, it is important not to go overboard with the technology and overload the students and oneself with extraneous problems.

Once the tools for the students are identified, one needs a plan for helping the students acquire them and the experience needed to interpret the output. Each time I have done a course with Maple, I have encountered students to whom I will be introducing the computer, as well as students who have never learned to type, so one must really plan carefully so that students' mathematical expertise and computational expertise can grow together and mutually reinforce each other. As a communications device, I have developed the "section accompaniment" worksheet, which I describe in more detail below. In my experience, tools for demonstrations need to be kept separate from tools students will need to tackle homework and laboratory assignments, so the code for classroom demonstrations and experiments is placed in "section supplement" worksheets, which I usually make available only in electronic form.

Basic resources for getting acquainted with the program are the "New User's Tour"(online), the online help, and books such as the Maple Learning Guide ${ }^{2}$, Classical Mechanics with Maple ${ }^{1}$, and Introduction to Maple $e^{4}$. The Maple Learning Guide ${ }^{2}$ and its companion Maple

Programming Guide ${ }^{4}$ have been written by Maple's programmers; they are good for browsing to

Proceedings of the 2001 American Society for Engineering Education Annual Conference \& Exposition Copyright (C) 2001, American Society for Engineering Education 
get ideas. The books by Greene ${ }^{1}$ and $\mathrm{Heck}^{3}$ I find even more useful. Greene's mechanics book ${ }^{1}$ is highly focused in scope, so the tools required are a very small subset of the Maple program. Nevertheless, the author demonstrates that it is possible to do a lot with very few commands. Greene $^{1}$ shows how to start to understand how the program works, how the commands interact with one another, and how to construct within the program problem solving strategies. Heck's Introduction to Maple ${ }^{3}$ is leisurely, and the author takes time to go into details of the construction of Maple. There are several chapters illustrating how use of Maple gives a different perspective on a seemingly standard problem. Moreover, both authors are interested in results, so they also describe situations where the program fails to produce a useful result and what rescue attempts you might make. In other words, they are oriented toward the real world, where not everything works all the time, and where sometimes you just have to make the best of it.

Although some points are probably obvious, it won't hurt to mention them. First, adequate help for students is necessary, and this includes showing the students the program in use in the classroom frequently. Second, one should realize at the outset that use of Maple will make computation less tedious for all the students, while simultaneously making mathematics "harder" for many students. In early stages of my courses, I provide many templates for standard problems, which naturally make solving routine problems very easy. Repetitive practice of special techniques for especially routine problems is replaced by repetitive practice of entirely general procedures. A familiar kind of "rote learning" is supplanted by what may be termed "rote thinking." The extent to which this actually occurs is certainly deserving of further study. As the course progresses, I require students to invest more effort in explaining problem setups and in interpreting and evaluating their results. Many students find that this shift from emphasis on computation to emphasis on explanation and evaluation makes the course more difficult than they had expected.

\section{Preparing a section accompaniment}

In this paragraph I would like to indicate some design principles I try to apply when I prepare a worksheet to accompany a section of a text. The golden rule of worksheet preparation is "Resist temptation". I try to limit myself to the introduction of at most one or two new commands per worksheet. Because each worksheet starts with a description of its purpose and a list of commands it introduces, a student can easily browse the worksheets for a forgotten command or option. I also try to show students only one way to do a procedure. The likelihood that a learner who knows about two procedures will confuse them and be unable extricate himself or herself from the resulting chaos is too high to risk. I also provide examples constructed using only commands the students are supposed to know. Sometimes it is interesting to try to reproduce in Maple computations and illustrations from the text. Occasionally, I also create special routines to animate such things as limit processes. This feature of Maple seems to have great possibilities for augmenting our current texts.

When it comes time to assign homework to be done with computer assistance, some caution is necessary. Some mathematics problems work beautifully on paper, when they are correctly done, but an attempt to plot the results on a computer screen may be a disaster: When the plotter tries to fit the graph into the screen, scaling may make invisible precisely the phenomenon one would like to illustrate. Other problems may require explanations of how to evaluate and

Proceedings of the 2001 American Society for Engineering Education Annual Conference \& Exposition Copyright (C) 2001, American Society for Engineering Education 
manipulate the output of a solver. "Forewarned is forearmed" goes the saying, so I find myself working as many potential homework problems on the computer as I can, in order to spare the students unpleasant surprises on the homework. Along this line, never, ever, try to present in class an example you haven't already tested. As the semester progresses, instructions accompanying homework assignments become more involved because the material becomes more challenging and I require the students to take more responsibility for preparing problem setups and interpreting solutions.

\section{Supporting students}

I have used the following techniques for providing help to students in their third semester of calculus and in differential equations courses.

- First, I encourage students to keep logbooks of the assigned Maple commands, with comments and cautionary notes that might explain how to trace error reports to a list of likely fixes for the error. Students soon learn that they should keep track of the punctuation and case of letters, but they are not used to having to read their work over with the level of attention required to find the "silly" mistakes that bring the program to its knees. The class manager program described below has just become available to us this term; it is an invaluable aid for providing timely help on this sort of problem. Distributing printouts of classroom demonstrations is good, but I think making available electronic versions of the demos is better.

- Second, I spend time in the lab with the students, by bringing the class into the lab and by scheduling office hours in the lab. Students need access to the course instructor in the lab because only a limited amount of help for students in mathematics courses is available from the lab proctors. Many of these proctors are computer science majors, who may take only two semesters of calculus, and who, therefore, may not be able to give help to students trying to set up problems in third semester calculus or differential equations. Support for students is also provided through software developed by a member of the Department of Mathematical Sciences computer operations group for viewing students' workspaces on the laboratory server; this is described below in the section on hardware and universal software.

For motivation, students have to understand that learning to use the Maple tools accounts for more than a token percentage of the grade. I construct each test so that $15 \%-20 \%$ of the grade depends on the students' ability to set up problems in Maple and to interpret Maple results. Since classes are often too large for the lab, the Maple portion of each test consists of take-home problems. For the first exam, I usually ask students to correct some standard errors in Maple code, to do a one or two-step computation in Maple, and to make a qualitative evaluation of their result. By the second exam, the take-home component usually includes problems that require several computations, and the qualitative discussion is also more sophisticated. The take-home portion of the final examination is usually similar to the take-home component for the second exam.

Proceedings of the 2001 American Society for Engineering Education Annual Conference \& Exposition Copyright (C) 2001, American Society for Engineering Education 
Once I had trouble with plagiarism by students on an exam. A constructive, but time-intensive, strategy to prevent plagiarism is to use Maple itself to generate an individual exam for each student. Then students can share technique and ideas, but they can no longer share answers. As a fall back position, my grading policy stipulates that when I find significant segments of worksheets that appear to be identical, then no one will get credit for the work. Fortunately, I have not yet had the occasion to enforce this policy. In a semester-long course, I also require students to use the computer to develop two writing assignments. On these occasions, students usually work without templates to use Maple as an exploratory tool.

Returning to the observation that using Maple makes the mathematics "harder" for some students, I would like to observe that it has a way of making mathematics more conceptual. At the start of the third semester of calculus, students begin their studies of functions of two variables by plotting graphs and reacting at a relatively superficial level with the Maple program. For example, they spend a lot of time correcting keystrokes. But when they react to an uninformative graph, they may need to study a function more closely to identify its domain and to estimate its range. Although these two concepts are mathematically fundamental, it is difficult to convey their importance to students working in the traditional algebraic manner. However, every student in a class that does a lot of plotting seems to gain an appreciation of the importance of "domain" and "range", as well as the concept of "rate of growth". To give another example, the student who fuzzily summarizes the procedure for finding maxima and minima of a function of one variable as "solve the derivative" will have difficulty negotiating a sequence of Maple commands to find and classify critical points. Indeed, in the study of critical points, which we locate by using Maple to solve the equations " $\nabla f=0$ ", students must analyze the Maple output to classify solutions as real or complex, or as inside or outside the domain of relevance to the problem. As courses progress, I require the students to write more complete explanation of their setups for word problems and more sophisticated interpretation of their problem solutions. As a consequence, there is no point at which a student can feel sure that "it's all downhill from here."

\section{Hardware and universal software}

Currently, students in courses offered by NMSU's Department of Mathematical Sciences use a computing facility that consists of 21 Gateway PCs running Windows 2000, two network printers, and a server. Any NMSU student can apply to the Department for access to Scientific Workplace, Scientific Notebook, Maple V release 5.1, and telnet. Students enrolled in mathematics courses are automatically provided with access to the Microsoft Office 2000 suite, Netscape 4.7, Internet Explorer 5.0, and Geometer's Sketchpad. Programs running on the lab server rebuild the hard disks of each laboratory machine during the night, so that manufacturer's default settings for each program are restored and student "additions" to machines are removed.

The login script for a student enrolled in a mathematics course also mounts the student's drive S, which is the student's private workspace, the student's drive M, which provides the relevant class directory, and, in some cases, the student's drive Z, which carries extra software appropriate for a particular course. Since many faculty members run Windows NT machines that are served by a

machine distinct from the laboratory server, the Department of Mathematical Sciences Computer Proceedings of the 2001 American Society for Engineering Education Annual Conference \& Exposition Copyright (C) 2001, American Society for Engineering Education 
Operations Group (MathCOG) prepares a link from the faculty member's desktop to the class directory in the computer lab. Thus, handouts prepared by a faculty member in Maple, for instance, may be copied by a simple "drag-and-drop" operation into the class directory in the lab. The usual "double click" on a file in the class directory starts the application used to prepare the handout and opens the file for the student. The class directory is read-only for the students, but they may copy files onto diskettes to take home with them, print files, or copy templates into homework assignments.

Faculty also have access to their students' workspaces on the drive $S$, thanks to a class manager program being developed by Mr. Chris Moyer, a student employee of the MathCOG. The program has been used for the second time this semester and will be refined further in the light of our experiences with it. When the faculty member starts the program, the user is prompted for course and section numbers, and then the program presents the list of enrolled students. This is a nontrivial problem, for approximately 4,000 students each semester have accounts on laboratory machines. Clicking on a student's name opens a list of files in the student's workspace, and clicking a student's file opens the file on the faculty member's desktop. At present, this feature makes it possible for an instructor and a student to discuss the student's work in the instructor's office, and corrections and comments can be entered into the student's worksheet. Students who work in the laboratory on the weekends sometimes email to me descriptions of problems encountered on an assignment, and I can use the class manager program to open their worksheets and enter advice and corrections. To date, not many students take advantage of this opportunity to get feedback and advice, but I expect that more and more students will catch on as they figure out the system. The program also makes it possible to transfer files from and to each student's workspace. When the program is fully developed, we will be able to have students submit homework electronically. Thanks to the class manager program, they could just leave their worksheets for their assignments in their private workspaces, and faculty could open, check, and correct them.

\section{Effects on the students}

A preliminary review of results of the final exams for Fall 2000 seems to indicate that the work with the computers seems to be paying off. The take home portion of the final exam consisted of two problems. For each student, the first problem required the student to make contour and gradient plots to approximately locate and classify the critical points of a polynomial function of two variables. Explanation of the reasoning from the geometry to the classification was required. Then the student was to use Maple's built in numerical solver to more precisely locate the critical points and apply the second derivative test to confirm formally the geometric classification of the critical points. In the final step, the student made a graph of the function illustrating the critical points that had been found. Thus, students were supposed to study critical points geometrically two ways, through level curve plots and through the graph, as well as numerically. The second problem required the student to set up and evaluate a triple integral. On both of these problems, students earned about 89 percent of the credit. On these two important topics, the approach that uses the computer extensively permits the class to complete correctly about 89 percent of what I ask them to do. This contrasts with the in class portion of the exam, where percentage scores on dropped as low as 49 per cent on one problem (to find an equation for a plane through three points).

Proceedings of the 2001 American Society for Engineering Education Annual Conference \& Exposition Copyright (C) 2001, American Society for Engineering Education 
For Fall 2000, I also decided to survey the students in my course to assess their attitudes about the Maple-assisted approach to the course. Seventeen questionnaires were distributed and six were returned. The individual questions, as well as the distribution of the responses, are shown below. It is not so surprising that the responses exhibit divergent opinions on questions 6 and 7 below, asking if the use of the computer was experienced as an extra burden. However, the uniformity of response on other questions is encouraging. To sum up, students at this level feel that they should be exposed to the use of mathematical software to solve problems. They prefer learning to use a package that can be transported from one course to another rather than a specialized package. They all seem to agree that the graphical facilities available in Maple seem to help them understand the mathematics they are trying to learn, and are pretty sure computer experiments help them better understand the idea of limit. In particular, how the graphical facilities are helping them seems to deserve further study. Whether their hand calculation skills have improved or not seems to be a more problematic issue.

1. It is appropriate for instructors to use mathematical software in a course at this level.

Strongly agree Agree Probably Not at all No opinion

$\begin{array}{lllll}3 & 1 & 2 & 0 & 0\end{array}$

2. It is appropriate for students to have access to the same software as the instructors in a mathematics course at this level.

Strongly agree Agree Probably Not at all No opinion

$\begin{array}{lllll}5 & 1 & 0 & 0 & 0\end{array}$

3. It is appropriate to introduce students in one mathematics course to mathematical software that can be used in other advanced mathematics courses.

Strongly agree Agree Probably Not at all No opinion

$\begin{array}{lllll}3 & 3 & 0 & 0 & 0\end{array}$

4. It is appropriate to introduce students in one mathematics course to mathematical software that is suited to that course only.

Strongly agree Agree Probably Not at all No opinion

$\begin{array}{lllll}0 & 0 & 3 & 3 & 0\end{array}$

5. The electronic versions of the section accompaniments are more useful than the printed versions.

$\begin{array}{ccccc}\text { Strongly agree } & \text { Agree } & \text { Probably Not at all } & \text { No opinion } \\ 3 & 1 & 0 & 0 & 2\end{array}$

6. The need to learn computer commands hinders my learning and understanding of general procedures.

Strongly agree Agree Probably Not at all No opinion

$\begin{array}{lllll}1 & 1 & 0 & 4 & 0\end{array}$

7. Performing basic calculations with computer software frees me to concentrate on learning and understanding general procedures.

Strongly agree Agree Probably Not at all No opinion

$\begin{array}{lllll}2 & 2 & 0 & 2 & 0\end{array}$

8. Drawing pictures with the computer has contributed to my understanding of the geometric content of the subject.

Strongly agree Agree Probably Not at all No opinion

$\begin{array}{lllll}4 & 2 & 0 & 0 & 0\end{array}$

Proceedings of the 2001 American Society for Engineering Education Annual Conference \& Exposition Copyright (C) 2001, American Society for Engineering Education 
9. Checking hand calculations with the computer has improved my ability to calculate by hand.

$$
\begin{array}{ccccc}
\text { Strongly agree } & \text { Agree } & \text { Probably } & \text { Not at all } & \text { No opinion } \\
2 & 1 & 3 & 0 & 0
\end{array}
$$

10. Performing numerical and graphical experiments with the computer has improved my understanding of limits.

Strongly agree Agree Probably Not at all No opinion

$\begin{array}{lllll}4 & 0 & 2 & 0 & 0\end{array}$

I hope to survey students from the version of the course I presented in spring 2000 to see how their opinions have developed. In future versions of the course I plan to incorporate one of the learning style inventory instruments to see if data obtained thereby leads to improvement in Maple material I prepare for my students.

\section{Bibliography}

1 Greene, R.L., Classical Mechanics with Maple, New York: Springer (1995).

2 Heal, K.M., Hansen, M.L., and Rickard, K.M., Maple V Learning Guide, New York: Springer (1998).

3 Heck, A., Introduction to Maple, New York: Springer (1996).

4 Monagan, M.B., Geddes, K.O., Heal, K.M., Labahn, G., \& Vorkoetter, S.M. Maple V Programming Guide, New York: Springer (1998).

5 Stewart, J. Multivariable Calculus Concepts and Contexts, Pacific Grove: Brooks/Cole (1998).

\section{ROSS STAFFELDT}

Ross Staffeldt is an Associate Professor of Mathematics at New Mexico State University in Las Cruces. Dr. Staffeldt received a B.A. degree in Mathematics from Columbia University in 1973, an M.A degree in Mathematics from the University of California at Berkeley in 1975, and a Ph.D. in Mathematics from the University of California at Berkeley in 1977. His main research interests are algebraic topology and algebraic K-theory.

Proceedings of the 2001 American Society for Engineering Education Annual Conference \& Exposition Copyright (C) 2001, American Society for Engineering Education 